survive and replicate. The variant virus, once it has replicated, could further mutate, replicate or be selected to avoid immune recognition; alternatively, if the original variant virus has additional growth advantages it will win out.

From these considerations, it follows that only non-cytopathic viruses can establish chronic carrier states by using the antagonistic approach. The results of these studies could therefore support the hypothesis that HIV is non-cyto- pathic in vivo, and that AIDS is therefore a consequence of T-cell-associated immunopathology $y^{2.11}$, as is already well established for hepatitis caused by $\mathrm{HBV}^{12}$

Paul M. Allen is in the Department of Pathology, Washington University, St Louis, Missouri, 63110, USA. RolfM. Zinkernagel is at the Institute of Experimental Immunology, University of Zürich, $\mathrm{CH}-8091$ Zürich, Switzerland.

\title{
Martians come out of the closet
}

\section{Monica M. Grady and lan P. Wright}

AT about the time that scientists and engineers were coming to terms with the loss of the Mars Observer spacecraft, a new and as yet unique sample of the martian crust was discovered on Earth. The identification of an unusual meteorite always creates a stir within the meteoritics community; when the find turns out to be a piece of Mars, then the excitement has an even greater edge. In a report in Meteoritics, D. W. Mittlefehldt ${ }^{1}$ describes the reassignment of ALH84001 (a meteorite from the Allan Hills region of Antarctica) from diogenite, a relatively common type of basalt from the asteroid belt, to an SNC-related meteorite in other words, probably from Mars. The affair has forced scientists not only to re-examine the criteria by which meteorites are pigeonholed into the current fairly rigid classification scheme, but also to re-evaluate models of petrogenesis on Mars, and, most particularly, to look again at hydrothermal processes which may have modified the martian crust.

One of the reasons that ALH84001 was not immediately recognized as an SNC meteorite is that it does not fit readily into either of the established subdivisions, shergottite (S) or nakhlite-Chassigny (NC). Instead, it represents a new class of martian material. Its dominant mineralogy is a homogeneous orthopyroxene, with minor chromite, maskelynite, apatite, pyrite and carbonate. The melt composition inferred from its mineralogy is intermediate between those calculated for the shergottites and the NC clan. ALH84001 fits into neither group, but possesses features common to both, implying that it forms an important link between the subdivisions.

The most immediately obvious accessory mineral phase in ALH84001 is a bright orange-coloured iron-magnesiumcalcium carbonate, containing minor amounts of manganese. The carbonates are present in two forms: as large grains up to $200 \mu \mathrm{m}$ across with complex, fine-scale compositional zoning, or as small single grains about $10 \mu \mathrm{m}$ in size, which are unzoned. The chemical analysis of the carbonates allows comparison to be made with terrestrial carbonates, and from this Mittlefehldt proposed that the carbonates in ALH84001 were formed by multiple influxes of fluid at temperatures possibly as high as $700{ }^{\circ} \mathrm{C}$. In other words, the new martian rock gives us evidence of a hydrothermal system on another planet.

The mineralogy of ALH84001 will undoubtedly help in working out martian geochemical cycles. Mars specialists have long maintained that carbonate reservoirs must exist on the planet, formed by interaction of the $\mathrm{CO}_{2}$-rich atmosphere with loose soil and ash covering the bedrock ${ }^{2}$. But there has been only poor evidence for these deposits -- no samples have been gathered directly from Mars, and spectral data are ambiguous. In contrast, carbonates are readily observed in SNC meteorites: Carr et al. ${ }^{3}$ were the first to infer the presence of carbonates in Nakhla and EETA79001 (a shergottite) from acid-dissolution experiments. They were followed by Gooding et al. ${ }^{4}$, who found carbonate deposits (mainly calcite) in the small cavities known as "vugs" in EETA79001.

Subsequent work has shown that almost all the SNC meteorites contain carbonates 5 , but never on the scale and abundance observed by Mittlefehldt. The $\mathrm{Fe}, \mathrm{Mg}$-rich composition is aiso distinct from that of other martian carbonates, which are mainly calcite; perhaps this implies that carbonates in ALH84001 had a different mode of formation.

The origin of carbonates in SNCs is an open question. As the highest concentrations have been identified in the Antarctic shergottite EETA79001, it has been suggested that they are simply Antarctic weathering products. Radiocarbon and stable carbon and oxygen isotope data have not always been straightforward to interpret. In contrast, the carbonate history of ALH84001 appears straightforward: carbonates that formed early in the history of the parent rock are coarsegrained and strongly zoned, from $\mathrm{Fe}-$ and Ca-rich endmembers to almost pure magnesite. These assemblages are frequently cut by fractures, along which carbonate grains are often displaced, indicating that they formed before a shock event cracked the rock. Together with the inferred high formation temperature, this is strong evidence that the carbonates are indigenous to ALH84001, and are not simply terrestrial weathering products.

A second generation of unzoned carbonates occurs within regions of crushed material. These grains are smaller than the zoned carbonates but have the same general composition, so they were probably formed by remobilization of early carbonates during subsequent shock events.

How could the carbonates have formed? Textural and mineralogical evidence indicate that formation conditions varied: the carbonates might have precipitated from a single fluid whose composition changed during cooling, or the ambient temperature might have remained roughly constant during multiple influxes of different fluids. We must look to analyses of the carbon and oxygen stable isotope compositions to distinguish between these possibilities. Material has already been distributed to three laboratories for analysis, and results are awaited with interest.

It has become increasingly apparent that a direct mission to collect Mars samples is unlikely this century, and possibly far into the next. The failure of Mars Observer and uncertainty over the fate of Mars 94 and Mars 96 have contributed to the general malaise surrounding martian science. We must therefore grasp every opportunity to study our neighbouring planet, and once again the Antarctic meteorite collection programme has delivered an invaluable sample to the scientific community. Meteoriticists have long delayed in unanimously recognizing Mars as the SNC parent body. As Mittlefehldt concludes in his paper: "It is time to come out of the closet and openly refer to those meteorites . . . as martian". Samples of Mars are available for study — and the recent recognition of ALH84001 shows that there is much worth studying. $\square$

Monica M. Grady is in the Department of Mineralogy, The Natural History Museum, Cromwell Road, London SW7 5BD, UK. Ian P. Wright is in the Department of Earth Sciences, The Open University, Walton Hall, Milton Keynes MK7 6AA, UK.

\footnotetext{
. Mittiefehldt, D. W. Meteoritics 29, 214-221 (1994)

2. Kahn, R. Icarus 62, 175-190 (1985).

. Carr, R. H., Grady. M. M., Wright, I. P. \& Pillinger, C. T. Nature 314. 248-250 (1985).

4. Gooding, J. 1., Wentworth, S. J. \& Zolensky, M. E. Geochim cosmochim Acta 52 . 909 -915 (1988) Wright L P. Grady M M \& Pillinger, C. T. Geochim. Wright. P.,Grady, M. M. \& Pillinger, C. T. Geochim cosmochim. Acta 56, 817-826 (1992).
} 